Original Article

\title{
Effects of joint position on the distraction distance during grade III glenohumeral joint distraction in healthy individuals
}

\author{
SAm-Sik PArk, PT, MS ${ }^{1)}$, Bo-Kyung Kim, PT, PhD ${ }^{1)}$, OK-Kon Moon, PT, PhD²), \\ Wan-Suk ChOI, PT, $\mathrm{PhD}^{1)^{*}}$ \\ 1) Department of Physical Therapy, College of Medical Health, International University of Korea: \\ B-dong, 5 floor Dongbu-ro 965, Munsan-eup, Jinju-si, Gyeongsangnam-do 660-759, Republic of \\ Korea \\ 2) Department of Physical Therapy, College of Medical Health, Howon University, Republic of Korea
}

\begin{abstract}
Purpose] The study investigated the effects of joint position on the distraction distance during Grade III glenohumeral joint distraction in healthy individuals. [Subjects and Methods] Twenty adults in their forties without shoulder disease were randomly divided into neutral position group (NPG; $n=7$ ), resting position group (RPG; $\mathrm{n}=7$ ), and end range position group (ERPG; $n=6$ ). After Kaltenborn Grade III distraction for 40s, the distance between glenoid fossa and humeral head was measured by ultrasound. [Results] The average distances between the humeral head and glenoid fossa before distraction were $2.86 \pm 0.81,3.21 \pm 0.47$, and $3.55 \pm 0.59 \mathrm{~mm}$ for the NP, $\mathrm{RP}$, and ERP groups. The distances after applying distraction were $3.12 \pm 0.51,3.86 \pm 0.55$, and $4.35 \pm 0.32 \mathrm{~mm}$. Between-group comparison after applying distraction revealed no significant differences between the NP and RP groups, while there was a statistically significant difference between the NP and RP groups, as well as between the NP and ERP groups. [Conclusion] Joint space was largest in ERP individuals when performing manual distraction. Key words: Joint position, Manual distraction, Glenohumeral joint
\end{abstract}

(This article was submitted Jun. 23, 2015, and was accepted Jul. 23, 2015)

\section{INTRODUCTION}

Manual distraction is a physical therapy technique used to increase range of motion (ROM) or to reduce pain in limited shoulder joints ${ }^{1,2)}$. The Kaltenborn-Evjenth concept defines distraction as the vertical distraction from the concave treatment surface. Manual distraction in the shoulder joint refers to the vertical distraction of the humeral head against the glenoid fossa. Although the treatment effects of distraction have been studied, the optimal distraction position during the procedure remains controversial.

Distraction is categorized as Grades I to III. Grade I is the force required to remove joint suppression without joint separation. Grade II is the force required to tighten the ligament and joint capsule following increasing tension. Grade III is the force necessary to separate the joint surface by adding additional power to the periarticular tissue during Grade II distraction. Grades I and II are used to control pain, while Grade III is used to increase $\mathrm{ROM}^{3}$ ).

The distance of a joint surface is related to its ROM. A

*Corresponding author. Wan-Suk Choi (E-mail: y3korea@ empal.com)

(C2015 The Society of Physical Therapy Science. Published by IPEC Inc. This is an open-access article distributed under the terms of the Creative Commons Attribution Non-Commercial No Derivatives (by-ncnd) License $<$ http://creativecommons.org/licenses/by-nc-nd/3.0/>. larger gap between joint surfaces creates more space for joint movement, which effectively increases the ROM. It is therefore important to determine the position that creates the largest joint space ${ }^{4}$. Physical therapy textbooks describe the resting position (RP) as the optimal posture for increasing $\mathrm{ROM}^{3)}$. However, recent research has suggested that the end range position (ERP) may be more effective than RP for increasing joint mobility ${ }^{5,6}$. RP-based treatment is still mainly performed to increase limited shoulder joint ROM in clinical settings in Korea, given the lack of evidence-based information for use of ERP.

The RP of the shoulder joint is defined as $55-70^{\circ}$ of shoulder abduction at $20^{\circ}$ of horizontal adduction ${ }^{7)}$. This posture results in easy joint surface separation due to relaxation of the joint capsule surrounding the shoulder ${ }^{3}$. The ERP of the shoulder joint is defined as maximal abduction and $90^{\circ}$ external rotation in a neutral rotation ${ }^{5}$. As the joint capsule and ligament are most taut in this position, the maximized contact between the two joint surfaces, results in joint separation is occurred minimally ${ }^{3}$. For this reason, it can be argued that distraction should be applied in RP rather than ERP, according to the Kaltenborn-Evjenth concept. However, this argument lacks evidence-based support. An unpublished pilot study (the data obtained with personal communication) by Gielen et al. ${ }^{8)}$ that applied distraction to four subjects with shoulder joints in $45^{\circ}$ abduction with simultaneous radiography found no joint separation between the humeral head and glenoid fossa. Conversely, Gokeler et 
al. ${ }^{9)}$ reported more prominent joint separation with distraction in RP compared to ERP.

The present study compared and analyzed the distance between the humeral head and glenoid fossa in the NP, RP, and ERP after Kaltenborn Grade III distraction in healthy adults.

\section{SUBJECTS AND METHODS}

\section{Subjects}

The participants included 20 adult residents of Changwon, Gyeongsangnam-do, Korea (9 females and 11 males). Individuals diagnosed with structural problems in their shoulder joints, severe osteoporosis, bursitis, lesions in their central or peripheral nervous systems, recent experience with dislocation or subluxation, and severe pain in the RP were excluded. Their average age and height were $42.9 \pm$ 8.16 years and $169.3 \pm 5.12 \mathrm{~cm}$, respectively. After receiving thorough explanations about the method and objectives of this study, verbal and written consent were obtained from all subjects prior to their participation. The potential risks were clearly explained to the subjects and they fully understood that they could rescind their participation at any time. This study received approval from the Institutional Review Board of the International University of Korea.

\section{Methods}

Twenty adults in their forties without shoulder disease were randomly divided into neutral position group (NPG), resting position group (RPG), and end range position group (ERPG). Subjects were placed in a supine position on a table at approximately waist level of the therapist. The indoor temperature was maintained around $23{ }^{\circ} \mathrm{C}$ so that the soft tissue did not tense, and all subjects wore sleeveless shirts. An experienced physical therapist certified in Kaltenborn Orthopedic Manipulative Therapy applied Grade III distraction to the right shoulder of each subject. Grade III distraction was defined as the force from the first stop when tension increases in formerly slack periaricular tissue to the last stop within the anatomic range ${ }^{10}$. Grade III distraction is the maximum force used by manual therapists in clinical situations to move a joint in the safety zone ${ }^{11)}$.

Distraction was applied to the right arm of each participants. NP was defined as a condition of parallel medial border and shaft of the humerus in neutral rotation $\left(90^{\circ}\right.$ rotation of the palm in the counterclockwise direction in anatomical posture $)^{5)}$. RP was defined as a position of $90^{\circ}$ of horizontal adduction and $55-70^{\circ}$ of shoulder abduction ${ }^{5}$. ERP was defined as a position of abduction and $90^{\circ}$ of external rotation in the neutral rotation ${ }^{5)}$. In the RP, a $20^{\circ}$ wedge was inserted in the armpit under the scapula for shoulder stability prior to applying the distraction technique. During the Grade III distraction, an assistant measured the distance between the humeral head and glenoid fossa by using ultrasonography and captured the image results as graphic files. To determine the measurement point, a virtual line was drawn connecting the ending point of the clavicle and the starting point of the axillary fold, and the transducer was connected to its middle point to confirm the location of the humeral head. The skin of the measurement point was cleaned and sufficient gel
Table 1. Effects of joint position on the distraction distance during Grade III glenohumeral joint distraction in healthy individuals

\begin{tabular}{lcc}
\hline Group & Before & After \\
\hline Neutral Position $(\mathrm{mm})$ & $2.86 \pm 0.81$ & $3.12 \pm 0.51$ \\
Resting Position $(\mathrm{mm})$ & $3.21 \pm 0.47$ & $3.86 \pm 0.55^{\dagger}$ \\
End Range Position $(\mathrm{mm})$ & $3.55 \pm 0.59$ & $4.35 \pm 0.32^{\star}$ \\
\hline
\end{tabular}

The values were expressed as the mean \pm SD.

'Significant difference between neutral position and resting position $(\mathrm{p}<0.05)$.

†Significant difference between neutral position and end-range position $(\mathrm{p}<0.05)$.

applied to permit use of a linear transducer MyLab One (Esaote, The Netherlands). Constant pressure was applied so that the measurement location was not excessively suppressed; measurements were obtained on a transverse scan. The average value of three independent measurements was used. To ensure standardized conditions for each measurement, all subjects followed the same sequence. Active arm elevation was performed 20 times before measurement in order to reduce variability due to viscoelastic properties of the shoulder joint and precondition of the soft tissues ${ }^{12,13)}$. The traction force was applied for $40 \mathrm{~s}$ before ultrasonography measurement, based on previous reports that the length of muscle-tendon units increases during $30 \mathrm{~s}$ of traction in laboratory settings ${ }^{14)}$.

IBM SPSS Statistics for Windows, version 20.0 was used for statistical analysis of data. One-way analysis of variance (ANOVA) was performed to examine the betweengroup difference of distance according to the traction grade. Bonferroni correction was used for post-hoc testing. The significance level was set at $\alpha=0.05$.

\section{RESULTS}

The average distances between the humeral head and glenoid fossa of the shoulder joint before distraction were $2.86 \pm 0.81,3.21 \pm 0.47$, and $3.55 \pm 0.59 \mathrm{~mm}$ for the NP, RP, and ERP groups, respectively. The distances after applying Grade III distraction were $3.12 \pm 0.51,3.86 \pm 0.55$, and $4.35 \pm 0.32 \mathrm{~mm}$, respectively. Between-group comparison after applying Grade III distraction revealed no significant differences between the NP and RP groups, while there was a statistically significant difference between the NP and RP groups, as well as between the NP and ERP groups (both $\mathrm{p}<0.05)$. Although the differences between the RP and ERP groups were not statistically significant, ERP increased more than RP (0.80 vs. $0.65 \mathrm{~mm})$ after distraction (Table 1$)$.

\section{DISCUSSION}

This study sought to determine the optimal position for maximum joint distance after manual distraction of the shoulder joint by a physical therapist. For this purpose, Grade III Kaltenborn distraction was applied to the shoulder joint of healthy adults in the NP, RP, and ERP groups, and the resulting distance between the humeral head and glenoid 
fossa was compared. The joint distance was the largest in the ERP group, followed by the RP and NP groups.

Joint distance is related to joint mobility. Shoulder joint mobility increases with larger joint space ${ }^{4}$. Hence, it is important to determine the optimal the treatment position that results in the largest joint space. However, the results in this study are believed to be an unlikely outcome in manual joint distraction in healthy glenohumeral joints in clinics. It has been argued that RP induces larger distances because it causes minimal joint tension ${ }^{10)}$ and discomfort ${ }^{15}$. . However, the joint space was the largest in the ERP group in this study. This is likely because joint traction for $30 \mathrm{~s}$ results in increased length of muscle-tendon units ${ }^{14)}$, even in the case of the ERP, where the soft tissue is taut. Moreover, the periarticular tissue that limits joint ROM was most stretched in the ERP or maximally closed packed position rather than in the $\mathrm{RP}^{5,16)}$. The present results are similar to previous observations in shoulder joints stretched for $40 \mathrm{~s}$. Similarly, Vermeulen et al. ${ }^{4}$ reported that end range mobilization techniques increased joint capacity and glenohumeral mobility. Passive distraction in end-range mobilization techniques has been recommended to obtain normal extensibility of the shoulder capsule ${ }^{17)}$.

The NP group showed the smallest space among the three groups in this study. Although the ligamentous structures are relaxed in the NP, rotator cuff muscles contribute to shoulder stability in the abducted shoulder in this position ${ }^{18)}$. It is possible that the joint space was smaller because the middle glenohumeral ligament functions as a principle barrier against frontal dislocation in the $\mathrm{NP}^{19)}$.

The RP in this study $(3.86 \pm 0.55)$ differed by $1.14 \mathrm{~mm}$ from a previous study ${ }^{20)}$ that reported a maximum separation of $5 \mathrm{~mm}$. The difference between studies could be attributed to subjective differences in the force applied by testers in each study or differences in subject health conditions and age. Although there was a difference of $0.49 \mathrm{~mm}$ between the RP and ERP groups ( $3.86 \pm 0.55$ vs. $4.35 \pm 0.32 \mathrm{~mm})$ in this study, it was not statistically significant.

This study had several limitations. First, the number of subjects was small. Moreover, as the sample consisted of healthy adults in their forties, the results cannot be generalized to other age groups or those with shoulder disease. Second, because distraction force was applied using Grade III Kaltenborn methods rather than applying a quantitative distraction force using a machine, the response to mechanical quantitative force was not measured. However, an experienced Orthopedic Manipulative Therapy physical therapist performed the evaluation to minimize inter-rater error of the manual distraction. Consequently, the joint space was the largest in the ERP group during Kaltenborn Grade III distraction of the glenohumeral joints of healthy adults.

\section{REFERENCES}

1) Wegner I, Widyahening IS, van Tulder MW, et al.: Traction for lowback pain with or without sciatica. Cochrane Database Syst Rev, 2013, 8: CD003010. [Medline]

2) Do Moon G, Lim JY, Kim Y, et al.: Comparison of Maitland and Kaltenborn mobilization techniques for improving shoulder pain and range of motion in frozen shoulders. J Phys Ther Sci, 2015, 27: 1391-1395. [Medline] [CrossRef]

3) Kaltenborn FM: Mobilization of the Extremity Joints, 3rd ed. Oslo: Olaf NorlisBokhand el, 1985.

4) Vermeulen HM, Obermann WR, Burger BJ, et al.: End-range mobilization techniques in adhesive capsulitis of the shoulder joint: a multiple-subject case report. Phys Ther, 2000, 80: 1204-1213. [Medline]

5) Hsu AT, Ho L, Ho S, et al.: Joint position during anterior-posterior glide mobilization: its effect on glenohumeral abduction range of motion. Arch Phys Med Rehabil, 2000a, 81: 210-214. [Medline] [CrossRef]

6) Yu IY, Jung IG, Kang MH, et al.: Immediate effects of an end-range mobilization technique on shoulder range of motion and skin temperature in individuals with posterior shoulder tightness. J Phys Ther Sci, 2015, 27: 1723-1725. [Medline] [CrossRef]

7) Magee DJ: Orthopedic Physical Assessment, 3rd ed. Philadelphia: WB Saunders, 1997.

8) Gielen J, Matthijs O, Paridon-Edauw GH, et al.: Unpublished data. 1993.

9) Gokeler A, van Paridon-Edauw GH, DeClercq S, et al.: Quantitative analysis of traction in the glenohumeral joint. In vivo radiographic measurements. Man Ther, 2003, 8: 97-102. [Medline] [CrossRef]

10) Kaltenborn FM: Mobilization of the Extremity joints: Examination and Basic Treatment Techniques. Osio Norlis Bokhandel, 1980.

11) Reeves B: Experiments on the tensile strength of the anterior capsular structures of the shoulder in man. J Bone Joint Surg Br, 1968, 50: 858-865. [Medline]

12) Bigliani LU, Pollock RG, Soslowsky LJ, et al.: Tensile properties of the inferior glenohumeral ligament. J Orthop Res, 1992, 10: 187-197. [Medline] [CrossRef]

13) Panjabi MM, Oxland TR, Yamamoto I, et al.: Mechanical behavior of the human lumbar and lumbosacral spine as shown by three-dimensional loaddisplacement curves. J Bone Joint Surg Am, 1994, 76: 413-424. [Medline]

14) Taylor DC, Dalton JD Jr, Seaber AV, et al.: Viscoelastic properties of muscle-tendon units. The biomechanical effects of stretching. Am J Sports Med, 1990, 18: 300-309. [Medline] [CrossRef]

15) Christopher H: Orthopaedic Manual Physical Therapy From Art to Evidence. F.A. Davis, 2015.

16) Hsu AT, Chang JH, Chang CH: Determining the resting position of the glenohumeral joint: a cadaver study. J Orthop Sports Phys Ther, 2002, 32: 605-612. [Medline] [CrossRef]

17) Wadsworth CT: Frozen shoulder. Phys Ther, 1986, 66: 1878-1883. [Medline]

18) Blasier RB, Guldberg RE, Rothman ED: Anterior shoulder stability: contributions of rotator cuff forces and the capsular ligaments in a cadaver model. J Shoulder Elbow Surg, 1992, 1: 140-150. [Medline] [CrossRef]

19) Gilles W, Pascal B, Gschwend N, et al.: Shoulder Arthroplasty. Springer, 2012, p 16.

20) Dvorak J, Dvorak V, Schneider W, et al.: Manuelle Medizin. Diagnostik, 5th ed. Stuttgart: Georg Thieme Verlag, 1997, p 240. 